\title{
Personnel Recruitment and the LaW: \\ Guidelines For Managers \\ of SMAll Business Firms
}

\author{
John P. Kohl \\ College of Business and Economics \\ The University of Nevada at Las Vegas \\ Las Vegas, Nevada \\ David B. Stephens \\ College of Business Administration \\ Utah State University \\ Logan, Utah
}

No owner or manager of a small business can escape the ever-present influence of the law on daily decisions which must be made. This problem has become acute during the past twenty-five years, with a continual growth of federal laws, regulations and court decisions which affect virtually every area of a company's operations. In addition to federal intervention in the workplace, managers and owners must also deal with a myriad of state and local laws and regulations.

These legal constraints pose special problems for individuals who want to ensure they are "doing the right thing" in such areas of personnel policies as compensation, benefits for employees, and questions which often arise in the area of equal employment opportunity (EEO). In fact, many owners-operators are unaware or uncertain of what they must be doing in order to assure that their personnel practices are both legal and fair.

There are a number of reasons for these problems. In recent years there has been an explosion of federal, state, and local laws and regulations which have sought to eliminate discriminatory employment practices. For many owners and operators of small business firms, the sheer numbers of such new requirements have been almost overwhelming. Possessing limited resources, many smaller firms have often found it impossible to study, evaluate, and implement additional requirements under the law.

Many of the EEO rules and regulations have affected a wide-range of personnel activities. For example, in dealing with the issue of "selection", it must be remembered that such decisions involve a variety of personnel actions. Equal employment requirements on selection affect not only the initial hiring decision, but recruiting practices, training decisions, layoffs and recalls, promotions, transfers, performance evaluations, and personnel assignments.

Journal of Business Strategies, Volume 5, Number 2 (Fall 1988) 
Finally, some small businesses may not fall under federal requirements ${ }^{1}$, but nonetheless must meet state requirements. In states where Fair Employment Statutes are more stringent than their federal counterparts, firms may need to consider not only federal requirements, but state as well.

Although no single study can address all employment issues, this article provides a basic foundation in assisting readers to a better understanding of specific problems involving recruitment and selection and to insure a sounder basis for legal action.

The starting point involves the recruitment practices of many furms. The cutting edge of this issue involves the dassified advertising, or "help wanted" ads, placed by firms. The wording of these advertisements is often questionable, if not blatantly illegal. Because of the visible nature of such advertisements, and their relationship to the entire selection process, this article will share the findings of previous studies $([4],[5])$ and offer suggestions regarding what can and should be done to assure sounder recruitment efforts.

First, a brief outline of what owners-managers can and cannot legally do in the area of personnel recruitment is presented. Second, the findings of a study of "help wanted" ads in major national newspapers are reviewed in order to point out problem areas for firms of all sizes. Special emphasis is placed on how smaller firms are affected. Finally, a number of recommendations are provided for small firms regarding ways in which their recruitment practices can better comply with current legislative and regulatory restrictions.

\section{What Does the Law Have to Say Regarding Recruitment Practices?}

The two primary federal laws affecting selection and recruitment practices are the Civil Rights Act of 1964 and the Age Discrimination in Employment Act of 1967. These laws establish specific "classes" or "groups" of protected individuals, and make it an illegal practice to discriminate in employment decisions based on race, religion, sex, color, national origin, and age ( 40 years of age and older). What the laws do not explain is how they are to be interpreted in specific fact situations. This interpretation is the domain of federal agencies and the courts.

Since the middle 1960 's, both the federal agencies and the courts have been hard at work seeking to explain exactly what can and cannot be done. As a result of interpretations by both the Department of Labor and the Equal Employment Opportunity Commission (EEOC), a number of regulations have arisen clarifying this issue. Although these regulations are not law, they have the effect of law until successfully challenged in the court. A brief sample of restrictions under the Civil Rights Act of 1964 and the Age Discrimination in Employment Act of 1967 is depicted in Figure 1.

\footnotetext{
${ }^{1}$ In general, businesses with 14 or fewer employees are exempt from coverage under most federal employment statutes.
} 
Figure 1

\section{A Brief Summary of Pre-Employment Practices and Federal Law}

1. The Civil Rights Act of 1964 and the Age Discrimination in Employment Act of 1967 cover all aspects of the selection process, including (but not limited to):

- Advertisements

- Questions on the application blank/form

- Questions asked during the screening interview and interviews

2. No information should be sought from candidates regarding their age, religion, sex, color, national origin, or race. Even questions such as "date of birth," or "year of graduation from high school" on application blanks should be avoided.

3. All advertisements for positions, to include "classified ads." should simply state job requirements. Requests for extrancous, unusual, or questionable information should be avoided unless it is a Bona Fide Occupational Qualification (BFOQ) - and the burden of proof of such BFOQ's falls squarely on the shoulder of the firm.

4. There are no BFOQ's for race or color. BFOQ's for sex, religion, national origin, and age have been viewed very narrowly by both federal agencies and the courts. As with "buyer beware," the rule of thumb for the small business owner or manager is: "advertiser beware."

\section{Some Key Points and Clarifications of the Law}

Although no summary of equal employment restrictions can ever be complete, those samples cited in Figure 1 shall serve as the focal point in discussing the recruitment of personnel.

BFOQ's. Although there are exceptions to the law called Bona Fide Occupational Qualifications (BFOQ's), such exceptions have always been narrowly interpreted by the agencies and the courts. BFOQ's are job qualifications (based on sex, religion, national origin, or age) which are allowed because they are considered to be reasonable job requirements. However, there are no exceptions for race or color, and even the other exceptions to the law are very limited. Examples include authenticity (a male model) for sex; national security restrictions for national origin; religious affiliation for religious organizations; and public safety for age (an airline pilot with mandatory retirement age at 60 ). When a company goes beyond such limited uses of BFOQ's, the burden of proof to show job relatedness falls squarely on the shoulders of the company. The tendency has always been for the agencies and courts to narrowly interpret, such exemptions.

Problems in establishing a BFOQ for a job can be illustrated by an example involving a Supreme Court decision involving sex and a BFOQ. Two decades ago, women were the sole persons eligible for the job of stewardess on airplanes. Pan American 
World Airways, Inc. was charged with sex discrimination by a male applicant. The company used as its $\mathrm{BFOQ}$ defense a survey of customers indicating a preference of female flight attendants, as well as the expert testimony of psychologists to show that women were better able to respond to flight emergencies. In its decision, the United States Supreme Court ruled out customer preference as a BFOQ, and consequently airlines employ both men and women for positions as flight attendants today [1].

Job Specifications Must Be Justifiable. Any specification based on religion, sex, national origin or age is highly suspect and subject to charges of discrimination by job applicants. Although firms no longer use such blatant terminology such as "help wanted - males," many firms continue to utilize other gender-based terminology such as "ladies," "young men," "girls," and so forth. In addition, many commonly used terms have evolved which utilize gender terminology. Examples include forman, and salesman.

Two Types of Age Discrimination. One area which is often confusing to employers involves age discrimination against employees 40 years of age and older. These prescriptions of age discrimination prohibit two types of discriminatory actions. First, it would be illegal to express a preference for a younger person in an ad, thereby discriminating against, a member of the protected class. For this reason, the earlier Department of Labor guidelines, and EEOC's acceptance of those interpretations, have prohibited ads which specify such terms as: boy, girl, young, teenage, 18 to 40 , under 40 , and so forth.

Second, age discrimination can also occur between members of the protected class, making this Act different from other civil rights legislation. Think about the possibility of a firm seeking to circumvent the intent of the law by making it a policy to recruit only individuals 40 to 45 , and thereby not recruiting or hiring individuals over 45 . On the surface, one could argue that fair employment practices were being extended to at least some member of the protected group. Such practices are deemed discriminatory under the law since they discriminate against some members of the protected group in favor of other members. As a result, ads should not specify terms or phrases such as recent retiree, retiree, 50 to 65 , and so forth.

\section{What are Business Firms Actually Doing in Recruiting Personnel?}

Up until this point, we have been discussing what firms can and cannot do legally. The issue remains: what are they actually doing in practice? The old adage, "the proof of the pudding is in the eating," could easily be applied to the issue of classified ads: "one proof of the understanding and commitment of firms to equal employment opportunity lies in the kinds of help wanted ads they place in newspapers." For this reason, researchers have been actively investigating the nature of newspaper "help wanted" ads for the past three years. These previous studies have provided a number of interesting findings regarding what business firms are actually doing in the area of personnel recruitment: 
1. The percentage of advertisements classified as questionable or illegal ranged from 2.4 to 5.8 percent of all ads analyzed $([4],[5])$.

2. The major problem areas identified involved firms advertising for specific job specifications based on sex, age, or bilingual abilities.

3. Of all organizations, trade and hospitality firms - two industries heavily dominated by smaller business operations - contained the largest percentages of questionable language in their classified advertisement.

As a result of this earlier work, and in order to better understand the nature of such questionable or illegal ads, the researchers decided to undertake a broader-based, national study of fifteen newspapers during the spring of 1986. In order to avoid regional bias, four papers were chosen from the northeast, four from the south/southeast, three from the midwest, and four from the west/southwest. The newspapers had a combined circulation of 7.5 million papers, and ranged in size from 250,000 to 1.7 million newspapers daily. A common date was chosen in order to assure uniformity of results, and a Sunday edition of the classifieds was analyzed in an attempt to maximize the number of such ads. Based on the previous discussion of illegal or questionable words which are often utilized in classified advertising, the researchers utilized terms and phrases such as those depicted in Figure 2 to classify words as being questionable or illegal under the law. It must be emphasized that this list is far from complete, but only illustrative of many of the terms and phrases identified during the study.

Figure 2

\section{Questionable Phrases in Help Wanted Advertisements}

$\begin{array}{ll}\text { Sex: } & \text { Man, woman, lady, boy, girl, gentleman, etc. } \\ & \text { Foreman, presserman, waiter, waitress, maid, counterman, host, } \\ & \text { bartendress, etc. } \\ \text { Age: } & \text { Boy, girl, semi-retired, 40-55, college student, young, etc. } \\ \text { Bilingual: } & \text { Bilingual preferred, bilingual required, Spanish required, etc. } \\ \text { National Origin: } & \text { Any specification for a specific national origin group. }\end{array}$

The analysis of the advertisements included all of the advertisements appearing in the fifteen Sunday editions of the newspapers. In all, more than 39,000 separate classified ads were counted, analyzed, categorized, and tabulated. A total of 1,077 ( 2.7 of the total) were considered to be questionable or blatantly illegal. The results of this study are reported below.

\section{Findings}

First, 68 percent of the total questionable ads were sex-based, and utilized either gender-based terms or overtly discriminated against one sex in favor of another. Although the gender-based terminology predominated in this group, many of the words 
which were considered to be gender terminology came suspiciously close to being overtly discriminatory (for example, sales ladies, or hostess).

Second, most of the sex-based ads were once again found in two industries - the trades (crafts, laborers, factory workers) and hospitality (non-managerial personnel such as waiters/waitresses, bartenders, etc.) ${ }^{2}$ Although trades and hospitality firms accounted for only 21.2 percent of all ads tabulated, these two industries had a total violation rate of 48.7 percent - almost half of all questionable advertising noted in this study. These findings are somewhat understandable, although not acceptable, because many of the firms in both industries tend to be dominated historically by titles which utilize gender terminology (such as repairman or waitress). However, as we will point out later, there are a variety of options to such gender terminology, and such sex-neutral terms can provide larger applicant pools for employers.

Third, age specifications accounted for 7 percent of all questionable ads tabulated in this study. Although this number may not appear significantly high, it does represent a continuing problem in recruitment practices. Further, it must be noted that since the early 1980's, the number of complaints regarding age discrimination filed with the Equal Employment Opportunity Commission have been second only to charges of sex discrimination.

Fourth, one type of ad which appeared in a number of papers which does not necessarily run contrary to federal law, but is illegal under many state statutes, was the request for "couples," particularly in the area of apartment house management. Most of the age specifications appeared in either this type of small business ad ("recentretiree" or "semi-retired"), or in hospitality ads (also for small businesses) looking for dancers who were "young girls." As indicated earlier, such ads were illegal specifications under the law.

Fifth, bilingual requirements continue to grow in number in the newspapers surveyed. In fact, this specification accounted for fully 24.4 percent of all questionable advertisements found in this study, and all such specifications were found in two newspapers - one in the northeast, the second in the southeast. This finding may also be of interest to the present readership since most of the ads involved secretarial personnel and receptionists for small offices.

The question of the status of bilingual requirements extends beyond the purposes of this article and has been discussed at length elsewhere [2]. As a job specification, bilingual ability must be proven to be job related, and not simply a "screening device" used to eliminate otherwise qualified applicants. Many positions may, in fact, require some facility in a second or even a third language. However, such requirements must be defensible is challenged.

${ }^{2}$ The remaining five classifications utilized included office/secretarial (typist, sectetary), professional (engineers, teachers), medical (physicians, nurses), managerial (managers, supervisors), and sales (salesman). 


\section{Suggestions to Business Owners and Operators}

This article has pointed to a number of problem areas in the recruitment of individuals for business organizations. In view of the findings of this study, the following suggestions are offered.

Become better acquainted with the law. This article provides the reader with a sample of what can and cannot legally be done under both the Civil Rights Act and the Age Discrimination in Employment Act in the area of recruitment. Readers who seek additional information can find such assistance through both the Federal Equal Employment Opportunity Commission, and (for federal contractors) the Office of Federal Contract Compliance Programs. Many private publications may also offer valuable assistance [6].

The discussion regarding help wanted advertisements should help readers who want to assure that their personnel policies are legal and within the bounds of the regulatory agencies. In this era of the "slipperiness" of all legislation, it is imperative that operators and owners assure that their recruitment practices do in fact fall within the requirements of the law. If one is unsure, he or she should seek additional help from applicable agencies, private publications, or legal counsel.

Check out applicable state laws which may affect your recruitment policies. This article has focused on two primary pieces of federal legislation. The legal rule of thumb is: federal law prevails over state law unless state law is more restrictive - and many states have equal employment opportunity legislation which extends beyond that discussed in this article. The small business owner and manager must make certain that any and all recruitment and selection procedures meet the standards of the state(s) in which the company operates. A telephone call to the office of the Equal Employment Opportunity Commission often serves as an excellent starting point for assuring that employment practices meet such state standards as well. However, State Fair Employment Practice Commissions can also provide needed and helpful advice, and are yet another source of assistance for owners and managers of small business firms.

Become more aware of traditional problem areas. We have wanted to see what firms - especially smaller firms in certain industries - are doing in order to recruit personnel. Although the percentage of questionable ads (less than 3 percent) may not appear to be large, it is nonetheless troublesome. Especially troublesome is the continued predominance of sex discrimination in advertising.

Seek alternatives which are non-discriminatory in wording. Many firms have already moved into sex-neutral job descriptions and specifications, 'and have learned how to avoid the use of terms and words which would be questionable. One excellent starting point is the Dictionary of Occupational Titles, published by Department of Labor and containing over 20,000 titles and job descriptions. This document is available through local libraries, and provides a basis for developing formal job 
descriptions and job specifications which utilize sex-neutral terminology. This survey identified a number of firms which used such terminology quite effectively in their "help wanted" ads - the word "greeter," for example, rather than "host" or "hostess."

At times the use of sex-neutral terms may appear to be cumbersome or difficult. This research also identified a number of creative ways in which business firms actually used traditional terms in help wanted ads while avoiding discrimination based on sex. For example, some employers chose to use both male and female terms (host/hostess, or waiter/waitress) in an attempt to communicate a desire to consider both male and female applicants. In other situations, the male or female term was used, followed by "M/F" to indicate once again that the employer actively sought applicants of both sexes.

Always remember that recruiting is a two-way street. Not only must a firm find the right person, it must also ensure that its policies and procedures as it recruits personnel leave those who apply with a good feeling regarding the business furm. Solid EEO is the beginning of such a process. Non-discriminatory, positive ads - devoid of discriminatory words, phrases, or job specifications - are the first step in advancing the image that a small business firm seeks to present to the community, job seekers, and the public-at-large.

\section{References}

1. Diaz v. Pan American World Airways, Inc. 404 U.S. 950 (1971).

2. Kohl, John P. "Legal Aspects of Bilingual Hiring Requirements." Texas Business Review (July-August 1983), pp. 188-191.

3. Kohl, John P. "Small Business Compliance With the Pregnancy Discrimination Act." Journal of Small Business Management (October 1983), pp. 49-53.

4. Kohl, John P., David B. Stephens, and Gerald McCaulley. "Questionable Advertising Practices by Business Firms: Results of a National Survey." Labor Law Journal (September 1986), pp. 660-667.

5. Kohl, John P., David B. Stephens, and H. Scott Stanfield. "Questionable Recruitment Practices: A Study of Newspaper Advertisements in the Southwest." Southwest Journal of Business and Economics (Winter 1985-1986), pp. 1-11.

6. Prentice-Hall Personnel Management Loose-Leaf Reports. Englewood Cliffs, NJ: Prentice-Hall Publishing Company. 